\title{
Robots in Retail Marketing: A Timely Opportunity
}

\section{Praveen Kumar Donepudi}

Enterprise Architect, Information Technology, UST-Global, Inc., Ohio, USA

*Corresponding Contact:

Email: praveen.donepudi@ust-global.com

Manuscript Received: 03 Sept $2020 \quad$ - Revised: 27 Oct $2020 \quad$ - Accepted: 05 Nov 2020

\begin{abstract}
Change is indeed inevitable. In the world full of technological advancements there has been a change in the retail marketing on how they conduct business. This has prompted a fast pace of automation and artificial intelligence (AI) as strategies that can be used to propel and reshape most business models. Machine intelligence is now more powerful, and it is changing the lives of people everywhere around the world. One such machine intelligence is the robot, which is almost being implemented on a daily basis to form part of retail marketing solution. Hence, it is important to critically analyze the significance of robots in retail stores and how the same can be used to change the current status quo into new business model. In answering the research questions, this research will adopt both secondary and primary data methods that will ensure that robust information is collected to meet the objectives of the study. Analysis of data revealed that change is inevitable in the retail industry, and it ought to be embraced in phases. The conclusion also revealed that robots have had both positive and negative impacts on the local stores. The idea of robots taking over various jobs in the industries may not be a good idea, but they have proved to be efficient and reliable.
\end{abstract}

Key Words: Automation, artificial intelligence, robots, retail marketing

\section{INTRODUCTION}

Robots are making a big splash into the retail market for the past few years. Their entrance, especially to the retail market, is characterized by competitiveness and cost-cutting initiatives. A good example is Amazon, which has been a leading disruptor in the retail arena. Their warehouses are now occupied by robots, which have changed their logistics operation with their increased efficiency and speed. According to Engelberger (2012), robots are no longer science fiction that people knew when they were invented in the 1930s. Machine intelligence is now more powerful, and it is changing the lives of people everywhere around the world. Also, when a robot is implemented, certain angles of its mechanical and electrical part has to process information like the I.T system. Nonetheless, the critical angles that have attracted more interest are the impact of robotics on the business environment. 
The impact of robots in the retail market is becoming inevitable and multi-dimensional, since the introduction of digital elements in the market such as clouds and analytics. According to the BCG group, the global market for robots is estimated to grow and reach over USD 80 Billion by 2025 . Hence, it is assumed that half of this amount will be allocated to the retail market. Nevertheless, this is a surprising fact since the retail market has always been the first adopter of advancement in technology. Also, automation has been an ongoing phenomenon in this industry, ever since it created efficiencies in the supply chain management. As a result, factory automations and warehouses are now under pressure to also innovate against the ecommerce retailers.

\section{Problem Identification}

The ironic truth of all time is the adage "timing is everything". In the early days, it was next to impossible to develop a robot solution for the retail marketing (Kaplan, 2020). The idea was met with worry and reluctance on the kind of image that the robot solution would look like in the stores. There was the fear of taking away jobs, interfering with the shoppers and so on. These were just concerns that started to fade away when the developments came into existence. However, some retails store tried to humanize the robot by ensuring there was less interference with the shoppers and the workers. Over time, there has been tremendous progress in the developments of robots and the likes of Amazon have been a big motivator and competitor to retailers on the integration of new technologies that are faster and has less human interference.

Robots are now rolling in into the retail markets, with some ranging six-foot-tall machines in many Giant food stores (Wirtz et al, 2018). For instance, in Walmart, there are autonomous shelf scanners that checks inventories. Also, at Lowe, a place of home improvement chain store, there is a "Lowebot" that assists in answering questions as well as offering assistance on where to find some items. As a result, these robots have helped workers in these stores from the usual tasks, which gives them ample time to interact with customers. This is just the beginning. There are many benefits associated with robots in retail stores. Among the main benefits of retail robots is the chance of capturing granular data concerning the products on the shelves, and observing consumers buying patterns, which increases accuracy and efficiency of inventory management. Thus, the key is to use the retail robots as data collectors in the internet-of-things (IoT), which is regarded as the most complicated network of objects in edge computing and cloud (Porambage, et al, 2018).

The IoT is able to create an intelligent digital ecosystem. Moreover, when combined with Artificial intelligent, IoT is able to propel the idea of Fourth Industrial Revolution; thus, changing how people conduct business, how they live, work and how they purchase their goods and services. Also, with the presence of robots in the stores, it shall mark the beginning of holistic IoT. For instance, the Auchan Retain in Portugal is the largest European retailer that launched the autonomous shelf-monitoring robot in its outlets. As eh robots maneuver around the shops, they capture pictures of all aisles and shelfs. These photos are then digitized, converted into metrics and give insights on pricing and out-of-stock details. Therefore, as it shall be demonstrated hereunder, retail markets need such incredible and valuable data where consumer demand is essential. As a result, this will capture the real competitive advantage for global retailers.

Retailers and various brands now need time to re-appraise how they develop their products and how they interact with their customers. Old business models may still be applicable; however, they are not built for the future that the world is entering. AI is no longer a 
Hollywood application, it is a powerful tool that retailers and brands need to use to relieve the pressure of business models. However, there is fear surrounding the habit of reorganizing a structure, which simply implies changing and disturbing the existing status quo. According to Donders, Enli and Syvertsen (2018), the reorganization of the structure implies a threat to the already vested interests and an upset to an already established method of handling things. The reality is that many leaders in the various industries have to constantly deal with the changes that occur as a result of increased competition, state regulations and advanced technologies (Donepudi, 2019). As a result, many stores are already adopting the small doses of change. Hence, in the pages ahead, there shall be a demonstration on how various retail stores are using robots to get closer to consumers as they continue to make profits.

\section{Aim and Objectives of the study}

The main aim of the study is to analyze the impact of robots in the business environment. It is not an easy task when an industry has to deal with a fast paced environment, especially on a day to day basis. On the other hand, the issue of innovation cannot be regarded as a luxury anymore; instead, many conversations revolve around the speed of change and how the same can be incorporated. The retail industry is no exception. Hence, one sure way that it can succeed in the fast paced environment is to challenge the current status quo and adopt AI methods. Therefore, this study will essentially help in future decision-making on how to integrate new business models.

\section{Research Question}

The study will be guided by two research questions as listed hereunder:

- Is there need for the retail markets to change existing status quo and adopt the use of robotics?

- Is change inevitable?

\section{Research Methodology}

The research will use both secondary and primary data methods. The use of these two methods will enable the study to have an element of both quantitative and qualitative data. Moreover, the use of both methods will ensue that the study not only produces robust and quality results but will also give an in-depth analysis of the aim of the study. There are numerous benefits of using both sources of data methods. For example, using secondary data methods tends to be less costly and there is a researcher tends to collect voluminous information. On the other hand, the primary data methods will be used as it will enable participants to adequately narrate on their lived experiences on the topic under discussion. Thus, surveys and observations will be mainly used to collect primary data. However, there shall be fewer participants who will be drawn from various retail stores. The secondary information will be sourced from journals, peer reviewed articles, and other vital documents. Once the data has been collected, it will be analyzed thematically by ensuring information is grouped and categorized into relevant themes.

Many research related to the adoption of a new technology has been done by different researchers and there has been different behavioral theories that has emerged on the users' behavior after adopting the technology. Hence, some of the behavioral theories used ae TRI, Technology Acceptance Model (TAM) and Theory of Planned Behavior (TPB). The history of emergence or all these behavioral models can be as a result of the rapid and dynamic introduction of technologies, which has an impact on how fast a user accept and adopt the 
technology. Thus, the rate at which a user adopts a technology depends of various factors such as security, convenience, comfort and speed. This implies that behavioral theory can also be used in institutions and organizations to determine if a technology can be adopted or not. Also, the theory can be used to establish the depth of the behavior and attitudes of the users of the technology, on whether it is challenging or not. Additionally, the theory enables the user to evaluate the technology according to his or her preference.

In the process of collecting both the secondary and primary data, the author had to thoroughly come up with a plan. As a result, there was a detailed planning process before the actual documentation. For instance, the researcher employed an eight step analysis that has elements of document analysis. These entailed creating a list of all participants, the data to be explored, and the sample size. Hence, for this particular research the participants were anonymous employees and customers of various retail stores in the United States. The data analysis was conducted in a four-stage review as demonstrated hereunder:

- The first step was to look up for a sampling criteria that is able to generate information in relation to the objective of the research. In this case, the sample frame were mostly customers shopping in the local stores and employees

- The second step is to determine the sample size. In this case, the researcher had to use a minimal sample size of 10 participants to minimize probability error

- The author also used five various types of sampling techniques including- systematic, cluster, random, stratified random and multi-stage techniques.

- Lastly was to ensure that the sample size taken represented the whole population.

Having been acquainted with the objectives of the study, collecting secondary data information was convenient. To be able to find useful secondary data, the primary source of information was from past literature reviews, case studies, and official data archives. For instance, the school library and the National Archives of the U.S, has been fundamental in providing research materials to this project, as well as other researchers. Also, the National Archives helps in teaching the communities with relevant real-life data that can be reworked, reanalyzed, and compared to other contemporary data that forms part of the culture and historical resources. Moreover, the data gathered in this study were from a variety of documentary sources, ranging from journals, case studies, policy documents, both academic and non-academic documents, and some reviewed articles. The criteria for searching data was to initially locate the data, then obtain a more detailed description of the study. There were well-documented sets of data that came with the illustrations and the procedures used to collect the available data.

\section{Customers' Acceptance of the Robot Services}

The problem associated with customers accepting the services of the robots in the retail marketing forms part of the theoretical framework that was established by Parasuraman (2000). Parasuraman designed the Technology Readiness Index (TRI) over a decade ago, comprising of 36-item scale on measuring the propensity of people embracing the cutting edge technologies. The theoretical framework in regards to customer acceptance in the robotic systems can be best analyzed by the extensive qualitative research done by Mick and Fournier (1998). All of these authors established eight technology paradoxes which includes - new vs obsolete; engage vs disengage; assimilation vs isolation; freedom vs slavery; incompetence vs competence; inefficiency vs efficiency; chaos vs control; and fulfilment vs creating needs. All these paradoxes were linked to the negative and positive needs of the 
customers from the impact of technology (Donepudi, 2020). Based on these experiment and other research, Parasuraman was of the view that the prevalence of a negative and positive feeling concerning technology depends from one person to another, and changes in their behavior in terms of acceptance depends on the propensity of people utilizing the new technology. For instance, the table below summarizes the strengths and limitations of robots to human.

Table 1: Pros and Cons of robots and humans

\begin{tabular}{|l|l|l|}
\hline & Strengths & Limitations \\
\hline \multirow{3}{*}{ Humans } & Trained easily & Prone to fatigue \\
\cline { 2 - 3 } & Excellent Dexterity & Geometrically less accurate \\
\cline { 2 - 3 } & Excellent Judgement & Sterility is not easy \\
\hline \multirow{3}{*}{ Robots } & Stable and untiring & $\begin{array}{l}\text { Huge problem in case of } \\
\text { complexity }\end{array}$ \\
\cline { 2 - 3 } & Can fight against radiation & Not easily adoptable \\
\cline { 2 - 3 } & Able to integrate multiple data & Limited dexterity \\
\hline
\end{tabular}

Other studies also identified the various consumer needs and motivation behind the acceptance of a new technology (Davis et al., 1989). However, by the time these studies were being conducted, the technological trends were still at its infancy stage. Hence, based on a successive scale, the TRI 2.0 having many compact numbers showed its validity as an equipment for showcasing technology acceptance and consumer preferences. The study also established that the key technology that will have the most implications for all the service provider are the robotic systems. Moreover, in a study conducted by Pires et al., (2011), a factorial analysis was carried out using structural equations and version 6.1, whose results shall be shown in table 1 below. The main factors adjusted on the sample data is on the optimism, innovativeness, discomfort and insecurity of customers. The measures of adequacy were NNFI CFI GFI and RMSEA.

Table 2: TRI Factorial analysis (Source: Pires et al., (2011)

\begin{tabular}{|l|l|l|l|l|l|}
\hline \multicolumn{1}{|c|}{ Factors } & \multicolumn{4}{c|}{ Adequacy measures } & Reliability \\
\hline & NNFI & CFI & GFI & RMSEA & \\
\hline Insecurity & 0,78 & 0,85 & 0,89 & 0,11 & 0,73 \\
\hline Discomfort & 0,80 & 0,84 & 0,88 & 0,08 & 0,73 \\
\hline Innovativeness & 0,95 & 0,96 & 0,95 & 0,07 & 0.74 \\
\hline Optimism & 0,93 & 0,95 & 0,90 & 0,06 & 0,84 \\
\hline
\end{tabular}

From the table the CFI, GFI and NNFI indices were all above 0,9 and the RMESA was within the interval of insecurity and discomfort constructs. On the other hand, the NNFI and CFI indices are below acceptable levels, and only RMSEA has the recommended limit of 0,008 which indicated an adjustment of the factors presented. Optimism indicated a positive attitude towards the new technology and how it offers flexibility and efficiency. Innovativeness shows the tendency of a person being a pioneer in the usage of the technology, while discomfort shows a lack of control over the technology and finally insecurity indicates a distrust in the technology. In a survey done by Keeling et al., (2013), customers were tasked to give their opinions on a technology mediated relationship. The results established that the human-robot interaction is less friendly but more task-oriented compared to the humanhuman relationship. 
Table 3: Characteristics of classes of technologies (Source: Dupree, 2002)

\begin{tabular}{|l|l|l|l|l|}
\hline Construct & Optimism & Innovativeness & Discomfort & Insecurities \\
\hline Pioneers & High & High & High & High \\
\hline Explorers & High & High & Low & Low \\
\hline Paranoids & High & Low & High & High \\
\hline Skeptics & Low & Low & Low & Low \\
\hline Laggards & Low & Low & High & High \\
\hline
\end{tabular}

The commitment of each type of TRI cluster to the market is made at different times. Indeed, explorers entered to the market before pioneers, pioneers before sceptics, skeptics before paranoids and paranoids before laggards. Thus, table 3 presents a clear profile of each type of user's beliefs of technology adoption. The above said, the market for robots is poised to take off with significance vengeance, especially with the establishment of $5 \mathrm{G}$ network and AI chips (Pouliot et al., 2018). While the idea seemed futuristic for most retail and wholesale shelves, that idea is already closer than majority think.

\section{Results AND Discussions}

The researcher had to evaluate the various technology factors using the TRI ad TAM Models through a hypotheses test, whose main task was to verify the four TRI factors- insecurity, discomfort, innovativeness and optimism. However, due to the sample size of 100 participants, and the large observable variables that accompanies the two models, the researcher had to work only with the factorial scores. Hence, the participants who were considered for the entire research were mainly clients at two retail markets -Walmart and Best Buy. The main focus was to establish the impact of robots in retail marketing.

\section{Robotics in Local stores}

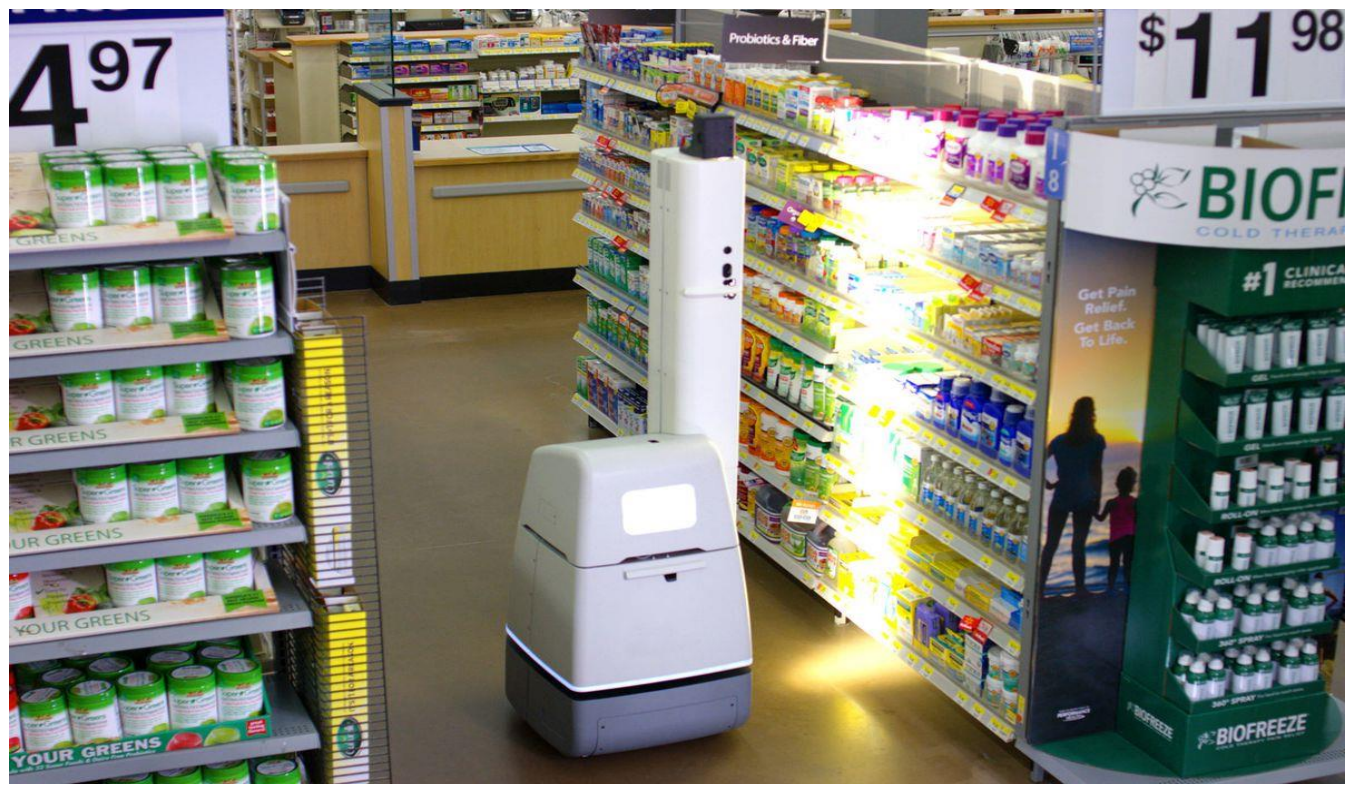

Figure 1: Self Scanning robot at Walmart stores. Image Courtesy of Vincent (2017) 
In the local stores, robots are typically used for logistics-related tasks, as well as customer service experience to improve the business's operational efficiency (Woo, Whittington \& Arkin, 2018). For instance, the delivery robots are tasked with bringing the stores to the consumers autonomously, the inventory robots are tasked with tracking the stores' inventories, and the in-store service roots provide directions to customers. Nevertheless, the retail robots are still new and in their early stages; however, as competition continues to heat up, robots are expected to be more prevalent in the retail stores. Walmart was the latest to introduce the shelf-scanning robots in almost 50 of their stores. The task of the robots is to check prices, inventory, and confirm any misplaced items. Additionally, the robots will also collect data - a move that will help Walmart to improve its inventory practices across its stores. The image below shows an example of a self-scanning robot at Walmart stores.

Another example is the Best-Buy's robot, otherwise known as Chloe. The robot looks like an industrial robot with arms that moves on chassis to select out what the customers want. In less than a minute, Chloe scoots around to pick what the customer wants from different rows of Video games tech accessories and DVDs (Mathur, 2019). In simple terms, customers can make purchases without interacting with a real person.

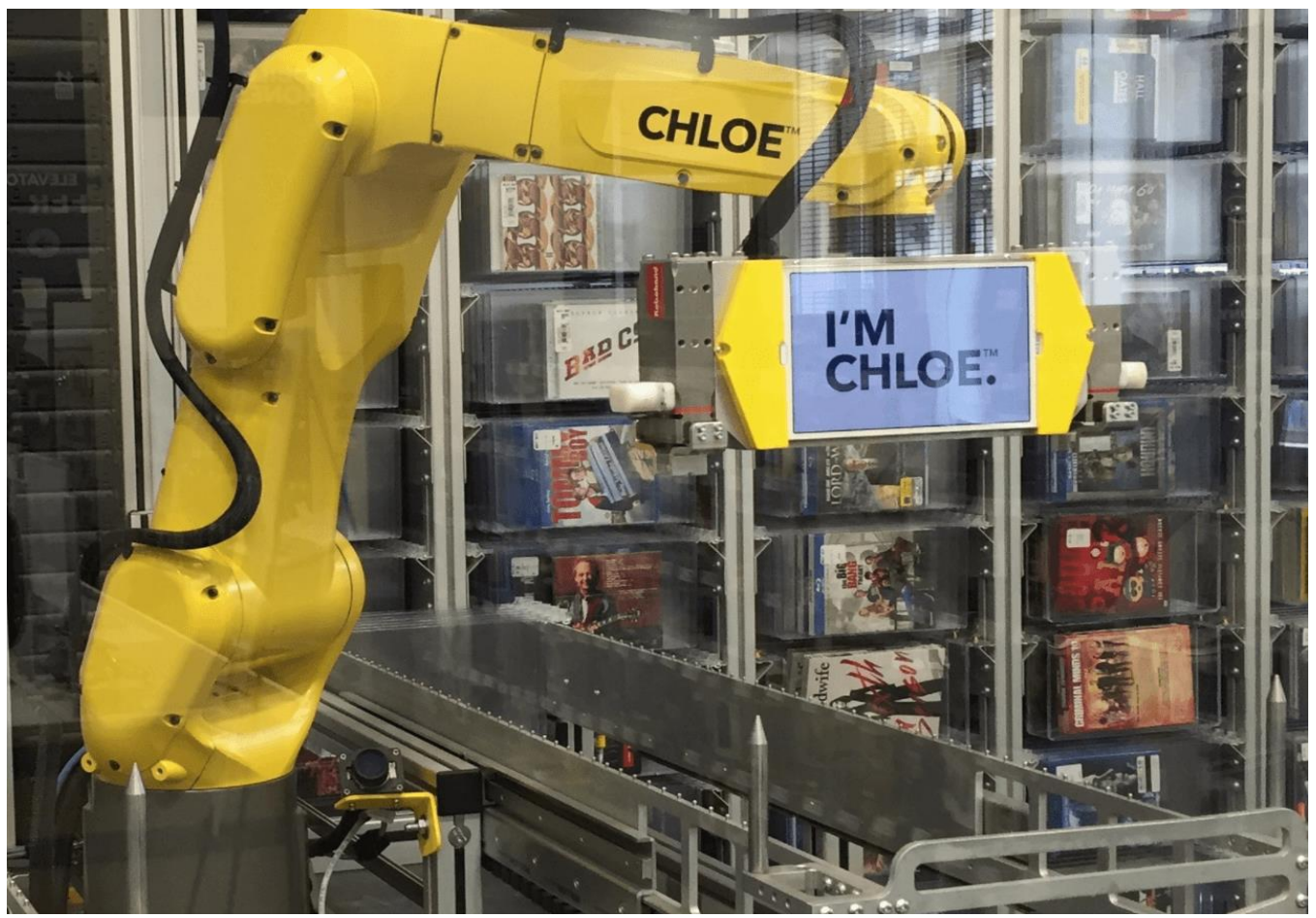

Figure 2: Best Buy Robot-Chloe. Image courtesy of Underwood (2020)

Chloe has set the pace of the AI, with his unique features. With its robotic arm and a chassis that moves along the shelves behind the clear partition, it enables customers to use touch screens to pick up their merchandise such as video games, movies and other accessories. It becomes more delightful watching the arms navigate through the shelves to retrieve purchases. In regards to future consideration for Chloe, the store aims to use it to simply the complicated customer needs, by simply selling products locked behind glasses. While these are just a few examples of robots operating in the local stores, it is clear that in the future, 
there will be typical robotic retail applications (Donepudi, 2018). Also, these developing technologies in robot automation will have a significant impact on profit margins and productivity.

\section{Challenges of using robots in Retail stores}

The rise of robots in local stores has unexpected side effects of depriving employees of the tasks that they once enjoyed doing. Instead, the workers have been complaining of feeling more robotic, and some of their main tasks are to train inscrutable robot colleagues. On the other hand, customers have also reported the act of co-existing with machines to be a bit confusing and alarming. For example, there are instances where some shoppers have reported being spooked by the Auto-scanner. In Walmart, the auto scanner stands almost seven feet tall, and once in a while, it creeps down the aisles to look for out-of-place items using a beam of light (Heller, 2017). Instead, some workers end up kicking the machine out of their way. Contrary, some employees and even workers have embraced the robots in the retail stores since the machines come in handy and they are most helpful (Ahmed \& Asadullah, 2020). Moreover, the robot's personalities have employee name tags, which become more charming and enticing. However, with the introduction of robotics, the dynamics and pace of work have changed. As a result, both consumers and workers are forced to respond to the nagging alerts from the robots.

Many Walmart workers had long feared that robots would replace their jobs, but the strange transition is seeing many of them work alongside the machines that are sometimes clumsy and brittle just like human nature (Azad et al., 2011). The management of Walmart has also explained that the machines have been helpful, and it allows workers to focus on their customers more, and they have been receiving positive responses that have prompted the retail store to expand more robot programs (Dirican, 2015). Moreover, the robots are also efficient, and they cut down on costs as they do not ask for raises, vacations, or even breaks. This helps the company to trim down on unnecessary costs and operate the stores with discipline.

Unfortunately, this has not been the case with Best-Buy robot, Chloe. Many consumers have been complaining of the machine breaking down unnecessarily in the Best Buy Support forum. For instance, in that forum, a customer complained of never having the opportunity of buying movies as Chloe is always down. Also, another customer complained of experiencing many occasions where he had to leave the store with no products. He blamed it on a maintenance issue. While defending themselves, the management noted that their demos and displays are always functional for the sake of the customers. While apologizing to those affected, they assured their customers that the maintenance team would look up the issue.

\section{FILLING THE GAP}

At this point, many people are already aware that having robots in most retail stores is a change that is inevitable, and also a gap that ought to be filled. These robots are involved in conducting so many tasks in the stores such as packing, assembling and handling products before they even reach the retail stores. In a similar manner, there are some robotics that are beginning to change how workers and shoppers purchase their products. First off, it has been proven that retail robots can manage to spot a mistake on the retail shelves. It is indeed frustrating when consumers and even cashiers have to pay for a product and realize that the price tag on the shelf is different from the main system price. Hence, this explains why 
Walmart has deployed mobile robots in 50 of their stores from Bossa Nova Robotics. The robots have cameras and they move through the aisles identifying problems associated with labels. Immediately they trace an error, they alert the humans who rectify the errors. Besides, robots can easily identify discrepancies that can be missed by a sale floor team.

Moreover, research has demonstrated that millennials make almost $\$ 200$ billion in terms of purchases every year compared to previous generations. Thus, Lantos (2014), argues that millennials tend to place a high value on convenience and will not mid whey are traded with automated experiences. Retailer have been left with no choice but to experiment with retail robots to handle the roles of humans in the stores. An example is given of Pepper the robot, which has a human-like face and carries a tablet on its chest. Nestle company had to use the robot to market its products in most Japanese retail markets (Lambert, 2018). Also, when customers see many empty spaces on the shelves, they automatically assume that the products have been sold out. That is why it is essential for retailers to watch out on their inventory levels and ensure the shelves are full. Nonetheless, robots can be a good technology to keep track of stock levels, by alerting the sales teams the items that have run out and the need to replenish stock. For instance, Amazon which sells an equivalent of more than 300 items per second had to engage Kiva the robot to retrieve products for the customers. Target had an experiment on a robot called Tally to check if the robot can detect when items ran low on the shelves. The experiment was not only successful but Tally has a scanner that can detect when a product is in the wrong shelf.

\section{CONCLUSIONS}

Robots have had both positive and negative impacts on the local stores. The idea of robots taking over various jobs in the industries may not be a good idea, but they have proved to be efficient and reliable. Robots are not only involved in packing, handling items, and assembling things, they are also changing how humans work and purchase goods at various local stores. Even though the case studies mentioned in this research were small trials, there are many possibilities and diversities of using retail robots, as they are the answer to creating a wealth of opportunities. Therefore, the use of automation and artificial intelligence can help retailers cut down on costs by maintaining the quality of service.

\section{REFERENCES}

Ahmed, A. A. A., \& Asadullah, A. (2020). Artificial Intelligence and Machine Learning in Waste Management and Recycling. Engineering International, 8(1), 43-52. https://doi.org/10.18034/ei.v8i1.498

Azad, M. R., Khan, W., \& Ahmed, A. A. A. (2011). HR Practices in Banking Sector on Perceived Employee Performance: A Case of Bangladesh. Eastern University Journal, 3(3), 30-39. https://doi.org/10.5281/zenodo.4043334

Davis, F. D., Bagozzi, R. P., \& Warshaw, P. R. (1989). User acceptance of computer technology: a comparison of two theoretical models. Management science, 35(8), 982-1003.

Dirican, C. (2015). The impacts of robotics, artificial intelligence on business, and economics. ProcediaSocial and Behavioral Sciences, 195, 564-573.

Donepudi, P. K. (2018). AI and Machine Learning in Retail Pharmacy: Systematic Review of Related $\begin{array}{llll}\text { Literature. } A B C \text { Journal } & \text { Advanced Research, 7(2), }\end{array}$ https://doi.org/10.18034/abcjar.v7i2.514

Donepudi, P. K. (2019). Automation and Machine Learning in Transforming the Financial Industry. Asian Business Review, 9(3), 129-138. https://doi.org/10.18034/abr.v9i3.494 
Donepudi, P. K. (2020). Crowdsourced Software Testing: A Timely Opportunity. Engineering International, 8(1), 25-30. https://doi.org/10.18034/ei.v8i1.491

Dupree, J. (2002). Techno-Ready Marketing: How and Why Your Customers Adopt Technology. Journal of Consumer Marketing, Vol. 19 No. 4, pp. 359-361. https://doi.org/10.1108/jcm.2002.19.4.359.1

Engelberger, J. F. (2012). Robotics in practice: management and applications of industrial robots. Springer Science \& Business Media. https://www.springer.com/gp/book/9780850386691

Heller, F. K. (2017). Technological innovation applied to walmart and tesco's supply chain (Doctoral dissertation), Universidade Nova de Lisboa. http://hdl.handle.net/10362/28327

Kaplan, A. (2020). Retailing and the Ethical Challenges and Dilemmas Behind Artificial Intelligence. Pantano, E. (Ed.) Retail Futures, Emerald Publishing Limited, pp. 181191. https://doi.org/10.1108/978-1-83867-663-620201020

Keeling, K., Keeling, D., \& McGoldrick, P. (2013). Retail relationships in a digital age. Journal of Business research, 66(7), 847-855.

Lambert, N. (2018). Designing companions, designing tools: social robots, developers, and the elderly in Japan. http://hdl.handle.net/1866/21239

Lantos, G. P. (2014), "Marketing to Millennials: Reach the Largest and Most Influential Generation of Consumers Ever", Journal of Consumer Marketing, Vol. 31 No. 5, pp. 401403. https://doi.org/10.1108/JCM-03-2014-0909

Mathur, P. (2019). Key Technological Advancements in Retail. In Machine Learning Applications Using Python (pp. 159-181). Apress, Berkeley, CA.

Mick, D. G., \& Fournier, S. (1998). Paradoxes of technology: Consumer cognizance, emotions, and coping strategies. Journal of Consumer research, 25(2), 123-143.

Parasuraman, A. (2000). Technology Readiness Index (Tri): A Multiple-Item Scale to Measure Readiness to Embrace New Technologies. Journal of Service Research, 2(4), 307320. https://doi.org/10.1177/109467050024001

Pires P.J., da Costa Filho B.A., da Cunha J.C. (2011). Technology Readiness Index (TRI) Factors as Differentiating Elements between Users and Non Users of Internet Banking, and as Antecedents of the Technology Acceptance Model (TAM). In: Cruz-Cunha M.M., Varajão J., Powell P., Martinho R. (eds) ENTERprise Information Systems. CENTERIS 2011. Communications in Computer and Information Science, vol 220. Springer, Berlin, Heidelberg. https://doi.org/10.1007/978-3-642-24355-4_23

Pouliot, R. C., Katsanis, C. J., \& Katsanis, A. (2018). Horizon 2020 transcended: the redesign of the AEC organization. Pngineering Organization Conference. https://espace2.etsmtl.ca/id/eprint/17964

Underwood, C. (2020). Robots in Retail-Examples of Real Industry Applications. EMERJ.

Vincent, J. (2017). Walmart is using shelf-scanning robots to audit its stores. The Verge.

Wirtz, J., Patterson, P. G., Kunz, W. H., Gruber, T., Lu, V.N., Paluch, S. and Martins, A. (2018). Brave new world: service robots in the frontline. Journal of Service Management, 29(5), 907931. https://doi.org/10.1108/JOSM-04-2018-0119

$--0-$

\section{How to Cite this Article}

Donepudi, P. K. (2020). Robots in Retail Marketing: A Timely Opportunity. Global Disclosure of Economics and Business, 9(2), 97-106. https://doi.org/10.18034/gdeb.v9i2.527 